\title{
Transcriptomic Analysis for Indica and Japonica Rice Varieties under Aluminum Toxicity
}

\author{
Peng Zhang ${ }^{1, *,+} \mathbb{C}$, Zhuoran Ding ${ }^{2,+}$, Zhengzheng Zhong ${ }^{1}$ and Hanhua Tong ${ }^{1, *}$ \\ 1 State Key Laboratory of Rice Biology, China National Rice Research Institute, Hangzhou 310006, China; \\ zhongzhengzheng@caas.cn \\ 2 Division of Biological Sciences, University of California, San Diego, CA 92093-0 116, USA; zhd007@ucsd.edu \\ * Correspondence: zhangpeng03@caas.cn (P.Z.); htonghz@126.com (H.T.); \\ Tel.: +86-0571-63370379 (P.Z.); +86-0571-63370336 (H.T.) \\ + These authors contributed equally to this work.
}

Received: 23 January 2019; Accepted: 21 February 2019; Published: 25 February 2019

check for updates

\begin{abstract}
Aluminum (Al) at high concentrations inhibits root growth, damage root systems, and causes significant reductions in rice yields. Indica and Japonica rice have been cultivated in distinctly different ecological environments with different soil acidity levels; thus, they might have different mechanisms of Al-tolerance. In the present study, transcriptomic analysis in the root apex for Al-tolerance in the seedling stage was carried out within Al-tolerant and -sensitive varieties belonging to different subpopulations (i.e., Indica, Japonica, and mixed). We found that there were significant differences between the gene expression patterns of Indica Al-tolerant and Japonica Al-tolerant varieties, while the gene expression patterns of the Al-tolerant varieties in the mixed subgroup, which was inclined to Japonica, were similar to the Al-tolerant varieties in Japonica. Moreover, after further GO (gene ontology) and KEGG (Kyoto Encyclopedia of Genes and Genomes) analyses of the transcriptomic data, we found that eight pathways, i.e., "Terpenoid backbone biosynthesis", "Ribosome", "Amino sugar and nucleotide sugar metabolism", "Plant hormone signal transduction", "TCA cycle", "Synthesis and degradation of ketone bodies", and "Butanoate metabolism" were found uniquely for Indica Al-tolerant varieties, while only one pathway (i.e., "Sulfur metabolism") was found uniquely for Japonica Al-tolerant varieties. For Al-sensitive varieties, one identical pathway was found, both in Indica and Japonica. Three pathways were found uniquely in "Starch and sucrose metabolism", "Metabolic pathway", and "Amino sugar and nucleotide sugar metabolism".
\end{abstract}

Keywords: aluminum toxicity; Indica; Japonica; transcriptomic analysis

\section{Introduction}

Over $50 \%$ of the world's arable land is acidic, and about $13 \%$ of global rice is produced on acidic soils [1]. The acidity of some soils is due to aluminum (Al), which is the most highly abundant metal in the earth's crust. Acidic soil containing solubilized trivalent $\mathrm{Al}\left(\mathrm{Al}^{3+}\right)$ will have $\mathrm{pH}$ values lower than 5.0. Not only is the growth of rice roots inhibited, but rice root systems can also be damaged by high concentrations of $\mathrm{Al}$ in the soil, which can both lead to significant reductions in rice yields [2,3]. Uncovering the genetic mechanisms of Al-tolerance in rice is the premise for rice Al-tolerance improvement.

Plant physiologists and breeders have been focusing on revealing the genetic mechanisms of Al-tolerance in rice [4-13]. Many quantitative trait loci (QTL) for rice Al tolerance have been reported in previous research, by using different mapping populations [7,10,14-18]. Furthermore, several genes related to aluminum tolerance in rice were cloned, i.e., ART1 [5], STAR1 [4], STAR2 [4], Nrat1 [6], OsFRDL2 [9], ASR5 [11], and OsEXPA10 [12]. Moreover, the genetic mechanism has not yet been 
dissected completely, due to the great complexity of Al-tolerance in rice. Thus, more studies are needed for the Al-tolerance of rice in the future. We summarized the QTL and genes, and found that these QTL and genes were not identical, for the most part, due to different mapping populations or $\mathrm{Al}$ toxicity concentrations. Moreover, these studies also showed that the genetic mechanisms of Al-tolerance in rice are very complicated, and they need more research in the future.

There are genetic variations in Al-tolerance within different rice cultivars. Generally, Japonica rice is more tolerant to $\mathrm{Al}$ than Indica rice. A number of studies have been carried out to determine the underlying genetic mechanisms that control the differential Al-tolerance in different rice cultivars, and many QTL for Al-tolerance have been identified by using various populations, including genome-wide association study (GWAS). However, no research has been dedicated to studying the mechanisms of rice Al-tolerance for Indica or Japonica separately. Rice (Oryza sativa L.) has two developed sub-species (i.e., Indica and Japonica rice) with abundant genetic diversity and remarkable intra-species variation for adapting to different ecological systems in the long history of cultivation and domestication. The ecological environments, especially the acidity levels in the soil, for Indica and Japonica rice, are not distinctly common between the two, so that the mechanisms of Al-tolerance between Indica and Japonica rice might be different. Hence, using different varieties of Indica or Japonica sub-species from previous studies might be an effective way of interpreting the great complexity of the genetic mechanisms of Al-tolerance. It would be very useful for the improvement of Al-tolerance in rice breeding, if the mechanism of Al-tolerance between Indica and Japonica could be proven to be different.

In the present study, transcriptomic analysis was performed to illustrate the different reactions of Indica and Japonica rice to Al toxicity. Transcriptomic analysis in the root apex for Al-tolerance in the seedling stage was carried out within Al-tolerant and sensitive varieties belonging to different subpopulations (i.e., Indica, Japonica, and mixed). These varieties were chosen from Ting's core collection, which is a core collection that is constructed from thousands of rice landraces. The results of this study will be very useful for dissecting the mechanisms of Al-tolerance in rice, and enhancing the resistance of elite cultivars against $\mathrm{Al}$ toxicity in acidic soils for rice breeders.

\section{Results}

2.1. The Identification of Varieties with Extreme Al-Tolerances and Susceptibilities, According to the Population Structure in Ting's Core Collection

The landraces with extreme Al-tolerance and susceptibility in each subgroup in Ting's core collection were selected by measuring the relative root elongation (RRE) in the presence of Al toxicity (Figure 1), i.e., Ba shi zi (Al-tolerant) and Chang ning wu qu nan tou zhan (Al-sensitive) in the subgroup of Indica, Ai you (Al-tolerant) and Kai xuan (Al-sensitive) in the subgroup of Japonica, and Bnlastog (Al-tolerant) and Hei ke da nuo (Al-sensitive) in the mixed subgroup.

\subsection{Transcriptome Sequencing and Sequence Quality}

There were 430,562,708 raw reads gained in total. The following quality control steps were performed: adapters were cut from the reads; reads having $\mathrm{N}$ base read frequencies of greater than $10 \%$ were filtered out; $3^{\prime}$-end base pairs with $\mathrm{Q}<30$ were cut; and low-quality reads were filtered out. The remaining 429,380,993 reads were used for downstream analyses (Table 1).

We performed a correlation analysis for the three biological replications, and the correlation coefficients ranged from 0.792 to $0.945(p<0.01$, Figure 2), which indicates a high correlation among the three biological replications. In this study, we used fragments per kilobase of the exon model per million mapped reads (FPKM), to demonstrate the expression levels of the genes. We defined a gene to be significantly differentially expressed when a gene's $\log _{2}$ (FPKM after Al treatment/FPKM without $\mathrm{Al}$ treatment) was higher than +1 and lower than -1 . The positive value of $\log _{2}$ (FPKM_after_Al 
treatment/FPKM_before_Al) showed that the expression of the gene was up-regulated, while the negative value showed that it was down-regulated.

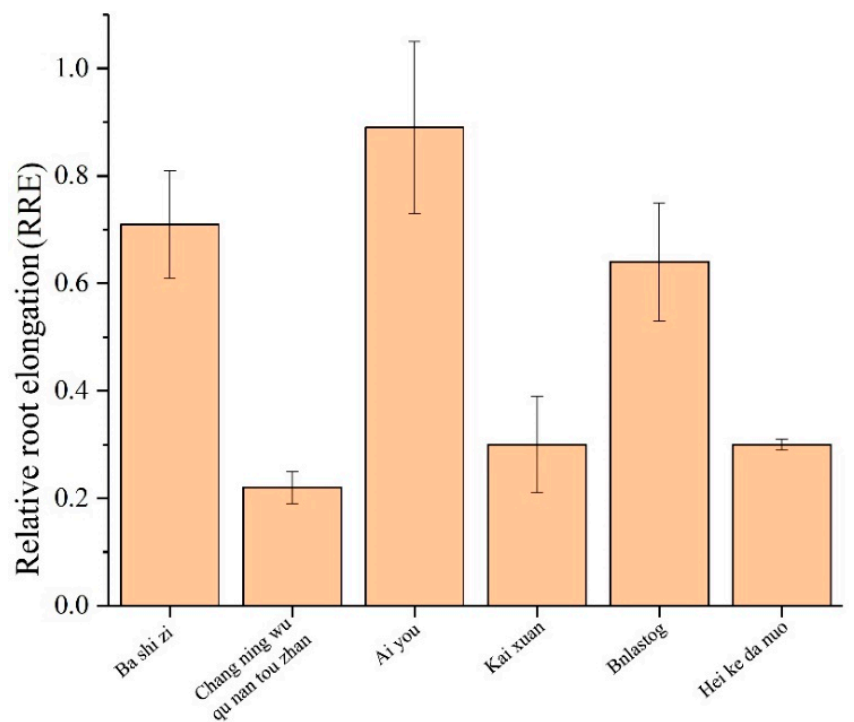

Figure 1. Relative root elongation (RRE) of six varieties in this study.

Table 1. Summary of RNA sequencing.

\begin{tabular}{|c|c|c|c|c|c|}
\hline Sample & $\begin{array}{c}\text { Raw Reads } \\
\text { (+Al, Average in } \\
\text { Three Replications) }\end{array}$ & $\begin{array}{c}\text { Clean Reads } \\
\text { (+Al, Average in } \\
\text { Three Replications) }\end{array}$ & $\begin{array}{l}\text { Raw Reads } \\
\quad(-\mathrm{Al})\end{array}$ & $\begin{array}{l}\text { Clean Reads } \\
\qquad(-\mathrm{Al})\end{array}$ & $\begin{array}{c}\text { Clean Data } \\
\text { Rates (\%) }\end{array}$ \\
\hline Chang ning wu qu nan tou zhan & $36,373,456$ & $36,180,456$ & $29,552,262$ & $29,405,604$ & 99 \\
\hline Ai you & $32,369,763$ & $32,211,179$ & $27,422,596$ & $27,260,342$ & 99 \\
\hline Kai xuan & $31,348,428$ & $31,176,510$ & $32,641,440$ & $32,476,890$ & 99 \\
\hline
\end{tabular}

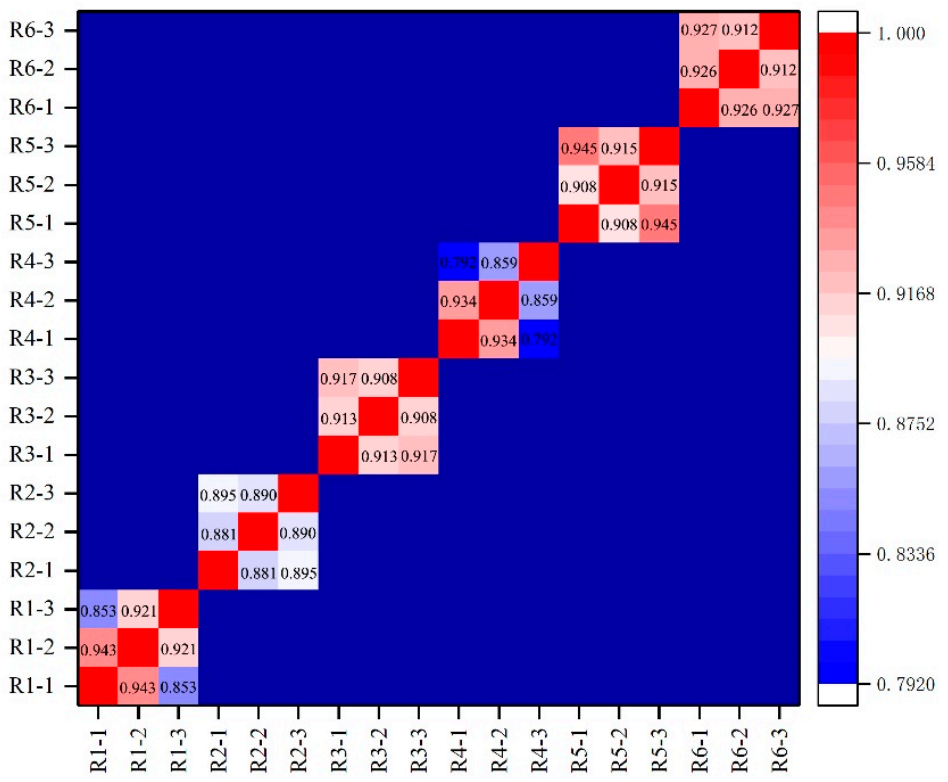

Figure 2. The correlation coefficients among the three biological replications. R1, R2, R3, R4, R5, and R6 represent Ba shi zi, Chang ning wu qu nan tou zhan, Ai you, Kai xuan, Bnlastog and Hei ke da nuo, respectively. 


\subsection{Comparison of Significantly Expressed Genes among the Three Al-Tolerant Varieties}

There were 3301 genes that were significantly up-regulated, both in Ba shi zi and Ai you, 4837 genes significantly up-regulated both in Ba shi zi and Bnlastog, 2695 genes significantly up-regulated both in Ai you and Bnlastog, and 2484 genes significantly up-regulated in all three varieties. There were 1294 genes that were uniquely up-regulated in Ba shi zi, 647 genes uniquely up-regulated in Ai you, and 1550 genes uniquely up-regulated in Bnlastog. There were 854 genes significantly down-regulated both in Ba shi zi and Ai you, 3309 genes significantly down-regulated both in Ba shi zi and Bnlastog, 768 genes significantly down-regulated both in Ai you and Bnlastog, and 709 genes significantly down-regulated in all three varieties. There were 1456 genes uniquely down-regulated in Ba shi zi, 257 genes uniquely up-regulated in Ai you, and 973 genes uniquely down-regulated in Bnlastog (Figure 3A).
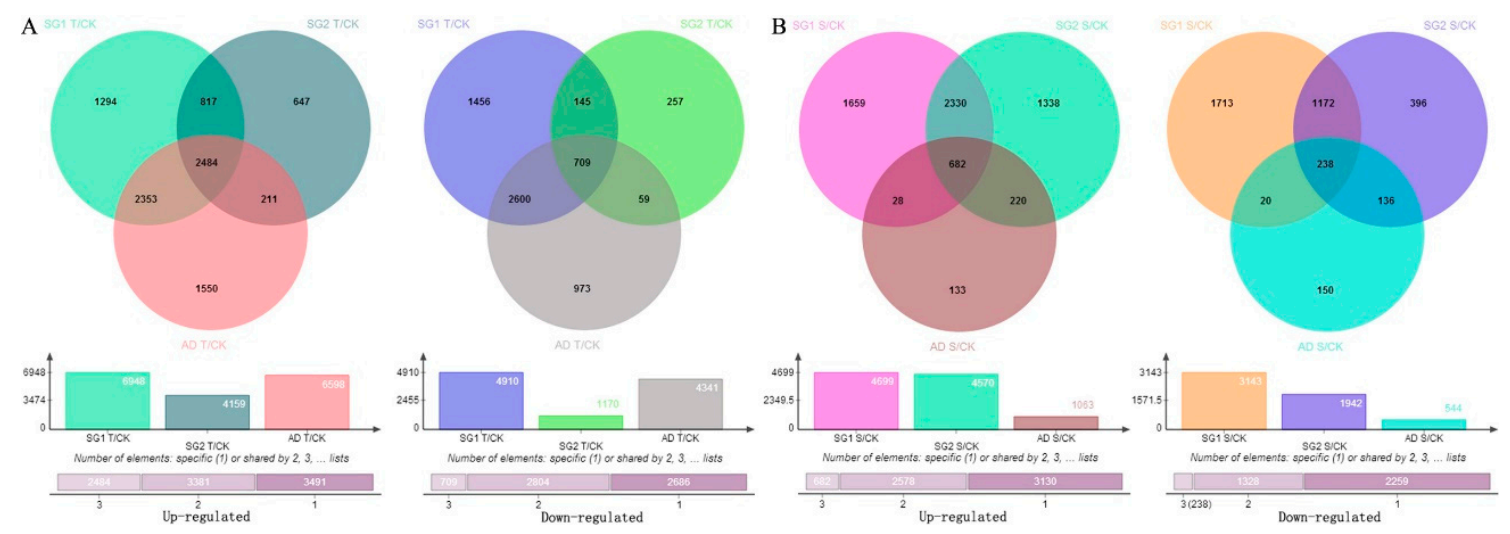

Figure 3. Venn diagram showing the numbers of differentially expressed genes among the Al-tolerant and Al-sensitive varieties. (A). Comparison among three Al-tolerant varieties; (B). Comparison among three Al-sensitive varieties. T, S, and CK represents Al-tolerant varieties under Al toxicity after $24 \mathrm{hr}$, Al-sensitive varieties under $\mathrm{Al}$ toxicity after $24 \mathrm{hr}$, and without $\mathrm{Al}$ treatment, respectively.

\subsection{Comparison of Significantly Expressed Genes among the Three Al-Sensitive Varieties}

There were 3012 genes that were significantly up-regulated, both in Chang ning wu qu nan tou zhan and Kai xuan, 710 genes significantly up-regulated both in Chang ning wu qu nan tou zhan and Hei ke da nuo, 902 genes significantly up-regulated both in Kai xuan and Hei ke da nuo, and 682 genes significantly up-regulated in all three varieties. There were 1659 genes uniquely up-regulated in Chang ning wu qu nan tou zhan, 1338 genes uniquely up-regulated in Kai xuan, and 133 genes uniquely up-regulated in Hei ke da nuo. There were 1410 genes significantly down-regulated both in Chang ning wu qu nan tou zhan and Kai xuan, 258 genes significantly down-regulated both in Chang ning wu qu nan tou zhan and Hei ke da nuo, 374 genes significantly down-regulated both in Kai xuan and Hei ke da nuo, and 709 genes significantly down-regulated in all three varieties. There were 1713 genes uniquely down-regulated in Chang ning wu qu nan tou zhan, 396 genes uniquely down-regulated in Kai xuan, and 150 genes uniquely down-regulated in Hei ke da nuo (Figure 3B).

\subsection{Gene Expression Patterns of Al-Tolerant and Al-Sensitive Varieties}

In order to further analyze the differences in Al-tolerance between Indica and Japonica, gene expression patterns of Al-tolerant and Al-sensitive varieties in three subgroups under $\mathrm{Al}$ toxicity were identified. Ba shi zi of Indica Al-tolerant and Ai you of Japonica Al-tolerant had significantly different expression patterns before and after applying the Al stress, and Bnlastog of mixed Al-tolerant had a similar expression pattern to Ba shi zi (Figure 4A). According to Cheng's index, Bnlastog is more closely related to Indica (Table 2). In addition, Chang ning wu qu nan tou zhan of Indica Al-sensitive and Kai xuan of Japonica Al-sensitive had significantly different expression patterns before and after applying Al stress, and Hei ke da nuo of mixed Al-sensitive had a similar expression pattern to 
Kai xuan (Figure 4B). According to Cheng's index, Hei ke da nuo is more closely related to Japonica (Table 2).

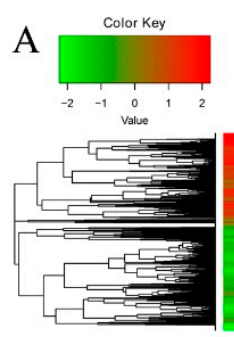

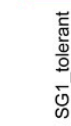
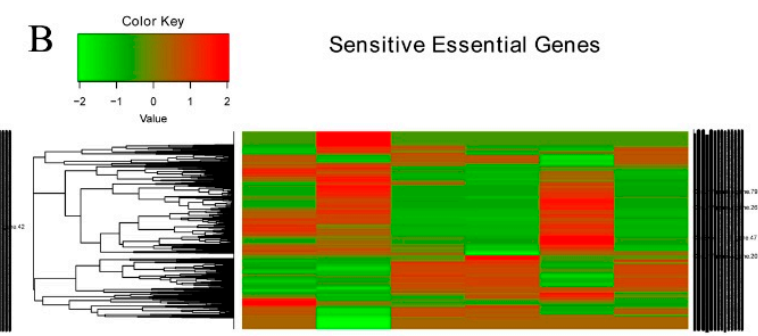

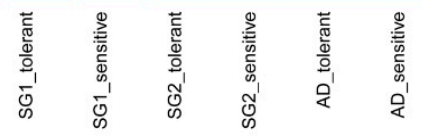

Figure 4. Expression patterns of differentially expressed genes among six varieties. (A) Comparison based on the genes relating to Al-tolerance; (B) Comparison based on the genes relating to Al-sensitivity. SG1, SG2, and AD represent Indica, Japonica, and the mixed subgroup, respectively.

Table 2. Cheng's index of six varieties in this study.

\begin{tabular}{ccc}
\hline Variety & Cheng's Index & Subgroup \\
\hline Ba shi zi & 9 & Indica \\
Chang ning wu qu nan tou zhan & 7 & Japonica \\
\hline Ai you & 21 & \\
Kai xuan & 18 & mixed \\
\hline Bnlastog & 13 & \\
\hline Hei ke da nuo & 17 &
\end{tabular}

Note: The Cheng's index is between 1-7, 8-13, 14-17, and 18-24 for typical Indica, Indica-clined, Japonica-clined, and typical Japonica rice, respectively.

\subsection{Classification of Differentially Expressed Genes of Al-Tolerant Varieties in Indica and Japonica}

As shown with the gene ontology (GO) analyses of the transcriptome data, Ba shi zi, in comparison with the Al-tolerant variety Ai you, had more differentially expressed genes categorized as a "cellular component", but fewer differentially expressed genes categorized as "molecular function" and "biological process" (Figure 5A). In addition, Chang ning wu qu nan tou zhan, in comparison with Kai xuan, had more differentially expressed genes categorized as "cellular component", but fewer differentially expressed genes categorized as "molecular function" and "biological process" (Figure 5B). Besides, pathway enrichment analysis of differentially expressed genes was performed using g:Profiler. We found that genes were uniquely enriched for Bas hi zi into "structural molecule activity (GO:0005198)", "transferase activity, transferring hexosyl groups (GO:0016758)", "structural constituent of ribosome (GO:0003735)", "transferase activity, transferring hexosyl groups (GO:0016757)" and "catalytic activity (GO:0003824)" in the category for "Molecular function", as well as "Carbohydrate metabolic process (GO:0005975)" in the category for "Biological process". Genes were uniquely enriched for Ai you and Bas hi zi into the "cell periphery (GO:0071944)", and "ribosome (GO:0005840)" in the category of "cellular component", respectively (Table S1). 

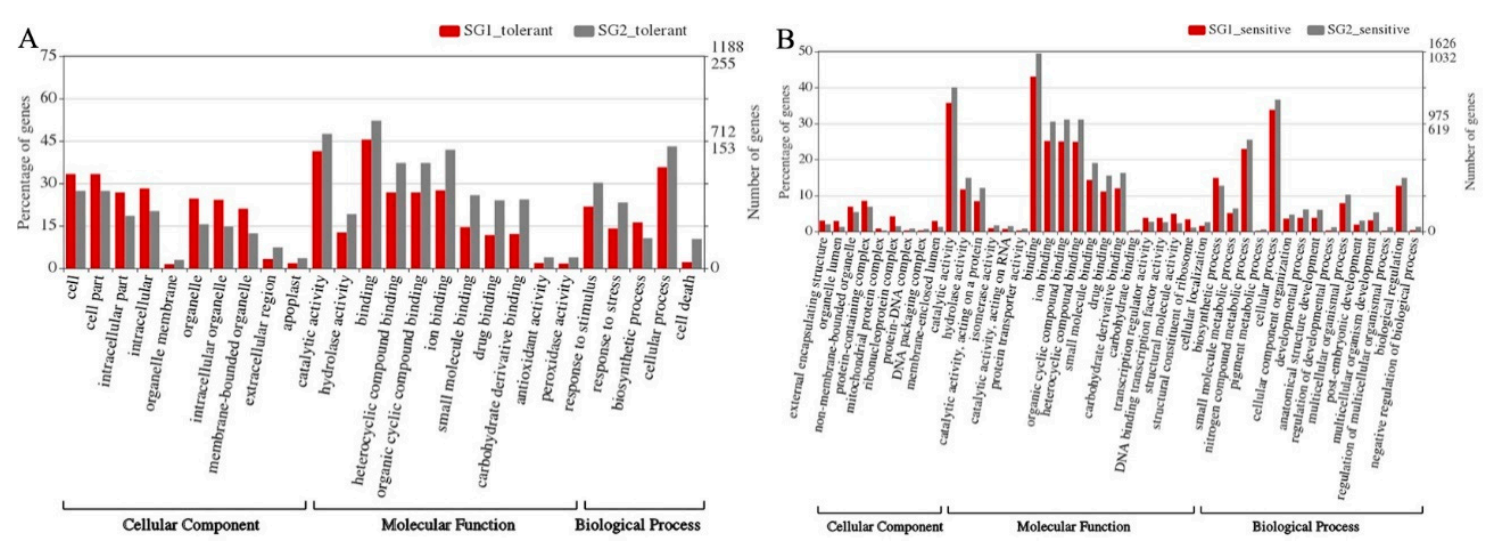

Figure 5. Gene ontology (GO) plot on genes with different expression patterns. (A). Genes with different expression patterns between Indica Al-tolerant and Japonica Al-tolerant sub-species; (B). Genes with different expression patterns between Indica Al-sensitive and Japonica Al-sensitive. SG1 and SG2 represent Indica and Japonica, respectively.

Moreover, we conducted pathway-based analysis for differentially expressed genes by the KEGG (Kyoto Encyclopedia of Genes and Genomes) pathway database. Six pathways were detected, both in Indica and Japonica Al-tolerant varieties. Eight pathways, i.e., "Terpenoid backbone biosynthesis", "Ribosome", "Amino sugar and nucleotide sugar metabolism", "Plant hormone signal transduction", "TCA cycle", "Synthesis and degradation of ketone bodies", and "Butanoate metabolism" were found uniquely for the Indica Al-tolerant variety Ba shi zi, while only one pathway (i.e., "Sulfur metabolism") was found uniquely for the Japonica Al-tolerant variety Ai you (Figure 6A,B). In the Al-sensitive sub-species, one identical pathway was found, both in Indica and Japonica. Three pathways were found uniquely in Chang ning wu qu nan tou zhan, i.e., "Starch and sucrose metabolism", "Metabolic pathway", and "Amino sugar and nucleotide sugar metabolism". Four Al-sensitive pathways were detected in Indica, and one was detected in Japonica. Hence, there was no figure to show the enrichment of the KEGG pathway for these two Al-sensitive varieties in the present study. The detailed information of the above KEGG pathways is summarized in Tables S2-S4.

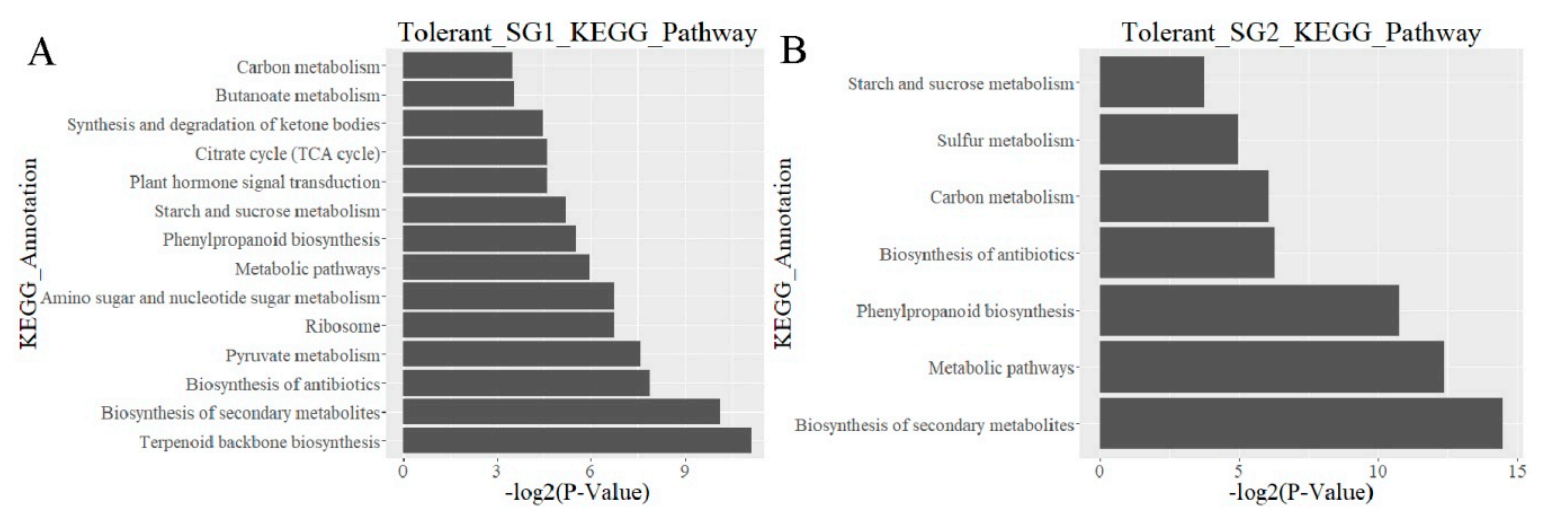

Figure 6. Enrichment analysis of differentially expressed genes of the KEGG pathway for Al-tolerant varieties. (A). Enrichment analysis for Al-tolerant variety in SG1 (Indica); (B). Enrichment analysis for Al-tolerant variety in SG2 (Japonica).

Besides enrichment analysis based on the KEGG pathway, further analysis was performed with the transcriptomic data, and 45 genes were found that had differential expressions between the Indica and Japonica subgroups, which merit further study. These included nine genes relating to abiotic stress, four relating to stress, four relating to the binding of heavy metals, 20 relating to cell walls, and three relating to gibberellin (Table 3). 
Table 3. Putative candidate genes that are differentially expressed between Indica and Japonica after Al toxicity treatment.

\begin{tabular}{|c|c|c|c|c|}
\hline Gene & Key Words & $\begin{array}{l}\text { Fold Change of Indica } \\
\text { Al-Tolerant Variety }\end{array}$ & $\begin{array}{l}\text { Fold Change of Japonica } \\
\text { Al-Tolerant Variety }\end{array}$ & Gene Annotation \\
\hline LOC_Os09g20390 & Abiotic stress & 2.21 & -3.87 & $\begin{array}{l}\text { Removes the phosphate from trehalose 6-phosphate to produce free trehalose. Trehalose } \\
\text { accumulation in plants may improve abiotic stress tolerance (By similarity) }\end{array}$ \\
\hline LOC_Os06g12310 & Abiotic stress & -2.24 & no & $\begin{array}{l}\text { Silicon transporter involved in the distribution of silicon in shoots. Is responsible for the } \\
\text { transport of silicon from the xylem to the leaf tissues. Silicon is beneficial to plant growth and } \\
\text { helps plants to overcome abiotic and biotic stresses by preventing lodging (falling over), } \\
\text { and increasing plant resistance to pests and diseases, as well as other stresses (PubMed:18515498) } \\
\text { In the nodes, is involved with LSI2 and LSI3 in silicon intervascular transfer, which is required } \\
\text { for the preferential distribution of silicon, such as the hyperaccumulation of silicon in the husk }\end{array}$ \\
\hline LOC_Os02g44230 & Abiotic stress & 3.78 & no & $\begin{array}{l}\text { Removes the phosphate from trehalose 6-phosphate to produce free trehalose. } \\
\text { Trehalose accumulation in the plant improves abiotic stress tolerance }\end{array}$ \\
\hline LOC_Os01g60020 & Abiotic stress & 2.92 & no & Probable transcription factor involved in stress response \\
\hline LOC_Os07g12340 & Abiotic stress & -2.24 & no & Probable transcription factor involved in the stress response \\
\hline LOC_Os06g43620 & Abiotic stress & 2.01 & no & May play a role in the abiotic stress response \\
\hline LOC_Os01g11414 & Abiotic stress & -3.07 & no & $\begin{array}{l}\text { May function as a sodium/calcium exchanger (NCX), and participate in the maintenance of } \\
\text { calcium homeostasis. May play a role in abiotic stress responses }\end{array}$ \\
\hline LOC_Os03g17700 & Abiotic stress & 2.05 & no & $\begin{array}{l}\text { Involved in disease resistance and abiotic stress tolerance-signaling pathways. Acts as a positive } \\
\text { regulator of drought, salt, and cold tolerance. Negatively modulates pathogenesis-related (PR) } \\
\text { gene expression, and broad-spectrum disease resistance (PubMed:12615946). Functions } \\
\text { downstream of CPK18 in a signaling pathway that represses defense gene expression, } \\
\text { and negatively regulates resistance to rice blast fungus. Phosphorylated by CPK18 at Thr-14 and } \\
\text { Thr-32, and is activated independently of MAP kinase kinase (MKK) phosphorylation }\end{array}$ \\
\hline LOC_Os09g35030 & Abiotic stress & no & -3.98 & $\begin{array}{l}\text { A transcriptional activator that binds specifically to the DNA sequence } 5^{\prime} \text {-[AG]CCGAC-3'. } \\
\text { Binding to the C-repeat/DRE element mediates high salinity- and dehydration-inducible } \\
\text { transcription. Confers resistance to high salt, cold, and drought stress }\end{array}$ \\
\hline LOC_Os02g09420 & Stress & -2.62 & no & May be involved in responses to stresses \\
\hline LOC_Os01g73580 & Stress & 2.85 & no & May play a role in sucrose partitioning during seed development, and in stress responses \\
\hline LOC_Os01g52030 & Stress & 2.69 & no & May be involved in the environmental stress response \\
\hline LOC_Os11g36719 & Stress & no & 3.87 & $\begin{array}{l}\text { Plant lipoxygenase may be involved in a number of diverse aspects of plant physiology } \\
\text { including growth and development, pest resistance, and senescence, or responses to wounding }\end{array}$ \\
\hline LOC_Os01g74300 & Bind to heavy metal & 3.26 & no & Metallothioneins have a high cysteine residue content; they bind various heavy metals \\
\hline LOC_Os01g10400 & Bind to heavy metal & 3.04 & no & Metallothioneins have a high content of cysteine residues that bind various heavy metals \\
\hline
\end{tabular}


Table 3. Cont

\begin{tabular}{|c|c|c|c|c|}
\hline Gene & Key Words & $\begin{array}{l}\text { Fold Change of Indica } \\
\text { Al-Tolerant Variety }\end{array}$ & $\begin{array}{l}\text { Fold Change of Japonica } \\
\text { Al-Tolerant Variety }\end{array}$ & Gene Annotation \\
\hline LOC_Os05g02070 & Bind to heavy metal & 3.93 & no & $\begin{array}{l}\text { FUNCTION: Metallothioneins have a high content of cysteine residues that bind various heavy } \\
\text { metals (Probable). They act as reactive oxygen species (ROS) scavengers in the cytosol. } \\
\text { They possess superoxide anion and hydroxyl radical scavenging activities in vitro } \\
\text { (PubMed:15220467). They play a role during root development, lateral root initiation, and seed } \\
\text { embryo germination, possibly by regulating levels of cytokinin }\end{array}$ \\
\hline LOC_Os12g38270 & Bind to heavy metal & 3.59 & no & Metallothioneins have a high content of cysteine residues that bind various heavy metals. \\
\hline LOC_Os08g33740 & Cell wall & -2.89 & no & $\begin{array}{l}\text { Probable mannan synthase which consists of 4-beta-mannosyltransferase activity on mannan } \\
\text { using GDP-mannose. The beta-1,4-mannan product is the backbone for galactomannan synthesis } \\
\text { by galactomannan galactosyltransferase. Galactomannan is a noncellulosic polysaccharides of } \\
\text { the plant cell wall }\end{array}$ \\
\hline LOC_Os06g39390 & Cell wall & 3.60 & no & $\begin{array}{l}\text { Involved in the incorporation of ferulate into the cell wall. May act as arabinoxylan feruloyl } \\
\text { transferase (PubMed:20012086). May function as } p \text {-coumaroyl-CoA transferase, which is } \\
\text { involved in glucuronoarabinoxylan modification }\end{array}$ \\
\hline LOC_Os10g42750 & Cell wall & -2.46 & 1.09 & $\begin{array}{l}\text { Thought to be a Golgi-localized beta-glycan synthase that polymerize the backbones of } \\
\text { noncellulosic polysaccharides (hemicelluloses) of the plant cell wall. Required for the synthesis } \\
\text { of a cell wall polysaccharide that is essential for root hair elongation, but not initiation. May be } \\
\text { the functional ortholog of Arabidopsis CSLD3/KOJAK }\end{array}$ \\
\hline LOC_Os01g60770 & Cell wall & -0.83 & 1.10 & $\begin{array}{l}\text { May cause loosening and extension of plant cell walls by disrupting non-covalent bonding } \\
\text { between cellulose microfibrils and matrix glucans. No enzymatic activity has been found. May be } \\
\text { required for rapid internodal elongation in deepwater rice during submergence (By similarity) }\end{array}$ \\
\hline LOC_Os05g19570 & Cell wall & -1.56 & 1.30 & $\begin{array}{l}\text { May cause loosening and extension of plant cell walls by disrupting non-covalent bonding } \\
\text { between cellulose microfibrils and matrix glucans. No enzymatic activity has been found. May be } \\
\text { required for rapid internodal elongation in deepwater rice during submergence (By similarity) }\end{array}$ \\
\hline LOC_Os05g19600 & Cell wall & -4.13 & 1.79 & $\begin{array}{l}\text { May cause loosening and extension of plant cell walls by disrupting non-covalent bonding } \\
\text { between cellulose microfibrils and matrix glucans. No enzymatic activity has been found. May be } \\
\text { required for rapid internodal elongation in deepwater rice during submergence (By similarity) }\end{array}$ \\
\hline LOC_Os03g05110 & Cell wall & -0.60 & 0.92 & $\begin{array}{l}\text { Involved in the attachment of the Gal residue on the third xylosyl unit within the XXXG core } \\
\text { structure of xyloglucan, the principal glycan that interlaces the cellulose microfibrils in plant cell } \\
\text { wall. Interacts with actin, and is required for proper endomembrane organization, and for the cell } \\
\text { elongation (By similarity) }\end{array}$ \\
\hline LOC_Os05g43530 & Cell wall & -2.06 & no & $\begin{array}{l}\text { Probable beta-1,4-glucan synthase, involved in the synthesis of the xyloglucan backbone instead } \\
\text { of cellulose. Seems to work simultaneously with xyloglucan 6-xylosyltransferase. Xyloglucan is } \\
\text { a type of noncellulosic polysaccharide g of the plant cell wall, and it consists of a glucan } \\
\text { backbone substituted by xylose, galactose, and fucose (By similarity) }\end{array}$ \\
\hline
\end{tabular}


Table 3. Cont

\begin{tabular}{|c|c|c|c|c|}
\hline Gene & Key Words & $\begin{array}{l}\text { Fold Change of Indica } \\
\text { Al-Tolerant Variety }\end{array}$ & $\begin{array}{l}\text { Fold Change of Japonica } \\
\text { Al-Tolerant Variety }\end{array}$ & Gene Annotation \\
\hline LOC_Os11g02350 & Cell wall & -3.28 & no & $\begin{array}{l}\text { Plant non-specific lipid-transfer proteins transfer phospholipids as well as galactolipids across } \\
\text { membranes. May play a role in wax or cutin deposition in the cell walls of expanding epidermal } \\
\text { cells and certain secretory tissues. May possess antifungal activities and protect the plant } \\
\text { against pathogens }\end{array}$ \\
\hline LOC_Os10g02380 & Cell wall & -2.97 & no & $\begin{array}{l}\text { May play a role in auxin-induced cell growth by generating hydroxyl radicals, which tends to } \\
\text { increase cell wall loosening }\end{array}$ \\
\hline LOC_Os04g49410 & Cell wall & -2.05 & no & $\begin{array}{l}\text { May cause the loosening and extension of plant cell walls by disrupting non-covalent bonding } \\
\text { between cellulose microfibrils and matrix glucans. No enzymatic activity has been found. May be } \\
\text { required for rapid internodal elongation in deepwater rice during submergence (By similarity) }\end{array}$ \\
\hline LOC_Os01g14660 & Cell wall & -2.74 & no & $\begin{array}{l}\text { May cause loosening and extension of plant cell walls by disrupting non-covalent bonding } \\
\text { between cellulose microfibrils and matrix glucans. No enzymatic activity has been found. May be } \\
\text { required for rapid internodal elongation in deepwater rice during submergence (By similarity) }\end{array}$ \\
\hline LOC_Os04g46650 & Cell wall & -3.05 & no & $\begin{array}{l}\text { May cause loosening and extension of plant cell walls by disrupting non-covalent bonding } \\
\text { between cellulose microfibrils and matrix glucans. No enzymatic activity has been found. May be } \\
\text { required for rapid internodal elongation in deepwater rice during submergence (By similarity) }\end{array}$ \\
\hline LOC_Os03g44290 & Cell wall & -3.20 & no & $\begin{array}{l}\text { May cause loosening and extension of plant cell walls by disrupting non-covalent bonding } \\
\text { between cellulose microfibrils and matrix glucans. No enzymatic activity has been found. May be } \\
\text { required for rapid internodal elongation in deepwater rice during submergence (By similarity) }\end{array}$ \\
\hline LOC_Os05g15690 & Cell wall & -4.37 & no & $\begin{array}{l}\text { May cause the loosening and extension of plant cell walls by disrupting non-covalent bonding } \\
\text { between cellulose microfibrils and matrix glucans. No enzymatic activity has been found. May be } \\
\text { required for rapid internodal elongation in deepwater rice during submergence (By similarity) }\end{array}$ \\
\hline LOC_Os01g09010 & Cell wall & -2.32 & no & $\begin{array}{l}\text { Involved in the incorporation of ferulate into the cell wall. May act as an arabinoxylan } \\
\text { feruloyl transferase }\end{array}$ \\
\hline LOC_Os10g42670 & Cell wall & 2.92 & no & $\begin{array}{l}\text { Catalyzes xyloglucan endohydrolysis (XEH) and/or endotransglycosylation (XET). Cleaves and } \\
\text { re-ligates xyloglucan polymers, essential constituents of the primary cell wall, and thereby } \\
\text { participates in the cell wall construction of growing tissues }\end{array}$ \\
\hline LOC_Os01g73790 & Cell wall & -2.01 & no & $\begin{array}{l}\text { Catalyzes the conversion of UDP-D-glucuronate to a mixture of UDP-D-apiose and } \\
\text { UDP-D-xylose. D-Apiose (3-C-hydroxymethyl-D-erythrose) is the only plant cell wall } \\
\text { monosaccharide with a branched carbon skeleton and, it is found in rhamnogalacturonan II } \\
\text { (RG-II), apiogalacturonan, and several apioglycosides (By similarity) }\end{array}$ \\
\hline LOC_Os11g02379 & Cell wall & no & 2.81 & $\begin{array}{l}\text { Plant non-specific lipid-transfer proteins transfer phospholipids, as well as galactolipids, } \\
\text { across membranes. May play a role in wax or cutin deposition in the cell walls of expanding } \\
\text { epidermal cells and certain secretory tissues }\end{array}$ \\
\hline LOC_Os06g01920 & Cell wall & no & 2.55 & $\begin{array}{l}\text { May cause loosening and extension of plant cell walls by disrupting non-covalent bonding } \\
\text { between cellulose microfibrils and matrix glucans. No enzymatic activity has been found. May be } \\
\text { required for rapid internodal elongation in deepwater rice during submergence (By similarity) }\end{array}$ \\
\hline
\end{tabular}


Table 3. Cont

\begin{tabular}{|c|c|c|c|c|}
\hline Gene & Key Words & $\begin{array}{l}\text { Fold Change of Indica } \\
\text { Al-Tolerant Variety }\end{array}$ & $\begin{array}{l}\text { Fold Change of Japonica } \\
\text { Al-Tolerant Variety }\end{array}$ & Gene Annotation \\
\hline LOC_Os12g29980 & Gibberellin & -2.41 & no & Transcription activator that plays a regulatory role in gibberellin-induced stem elongation \\
\hline LOC_Os03g51970 & Gibberellin & -2.69 & no & Transcription activator that plays a regulatory role in gibberellin-induced stem elongation \\
\hline LOC_Os02g45570 & Gibberellin & -3.43 & no & Transcription activator that plays a regulatory role in gibberellin-induced stem elongation \\
\hline LOC_Os04g52230 & Gibberellin & 3.02 & no & Catalyzes the conversion of ent-copalyl diphosphate to the gibberellin precursor, ent-kaur-16-ene. \\
\hline LOC_Os01g08220 & Gibberellin & -2.89 & no & $\begin{array}{l}\text { Catalyzes the 3-beta-hydroxylation of the inactive gibberellin precursors, leading to the } \\
\text { formation of bioactive gibberellins. In vitro, converts the precursors GA20, GA5, GA44, and GA9 } \\
\text { to the corresponding 3-beta-hydroxylated active products GA1, GA3, GA38, and GA4, } \\
\text { respectively. Involved in the production of bioactive GA for vegetative growth and development } \\
\text { (PubMed:11438692). Controls the elongation of the vegetative shoot and plant height by the } \\
\text { regulation of active gibberellin levels }\end{array}$ \\
\hline LOC_Os05g06670 & Gibberellin & 2.53 & no & $\begin{array}{l}\text { Catalyzes the 2-beta-hydroxylation of several biologically active gibberellins, leading to the } \\
\text { homeostatic regulation of their endogenous levels. Catabolism of gibberellins (GAs) plays } \\
\text { a central role in plant development. Controls the levels of bioactive GAs in the shoot apical } \\
\text { meristem, which regulate the vegetative-to-reproductive phase transition. In vitro, converts GA1, } \\
\text { GA4, GA9, GA20, and GA44 to the corresponding 2-beta-hydroxylated products GA8, GA34, } \\
\text { GA51, GA29, and GA98, respectively }\end{array}$ \\
\hline LOC_Os01g55240 & Gibberellin & 3.17 & no & $\begin{array}{l}\text { Catalyzes the 2-beta-hydroxylation of several biologically active gibberellins, leading to the } \\
\text { homeostatic regulation of their endogenous level. The catabolism of gibberellins (GAs) plays } \\
\text { a central role in plant development (PubMed:12736788, PubMed:18952778). In vitro, converts } \\
\text { GA1, GA20, and GA29 to the corresponding 2-beta-hydroxylated products GA8, } \\
\text { GA29-catabolite, respectively }\end{array}$ \\
\hline LOC_Os06g37364 & Gibberellin & -0.63 & 0.86 & $\begin{array}{l}\text { Catalyzes three successive oxidations of the 4-methyl group of ent-kaurene, giving kaurenoic } \\
\text { acid, a key step in gibberellins (GAs) biosynthesis. GAs, which are involved in many processes, } \\
\text { including stem elongation, play a central role in plant development }\end{array}$ \\
\hline
\end{tabular}




\section{7. $q R T-P C R$ Verification}

We randomly selected eight genes with significantly differential expressions after applying Al stress in Al-tolerant and Al-sensitive varieties. The expression levels of the above eight genes were verified by qRT-PCR (Quantitative reverse transcription-PCR) analysis, and they were significantly different in Nipponbare and Kasalath (Figure 7), which showed that the transcriptome sequencing results were reliable.

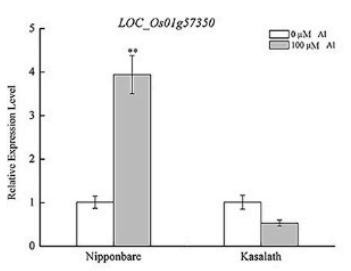

LOC_Os01957880
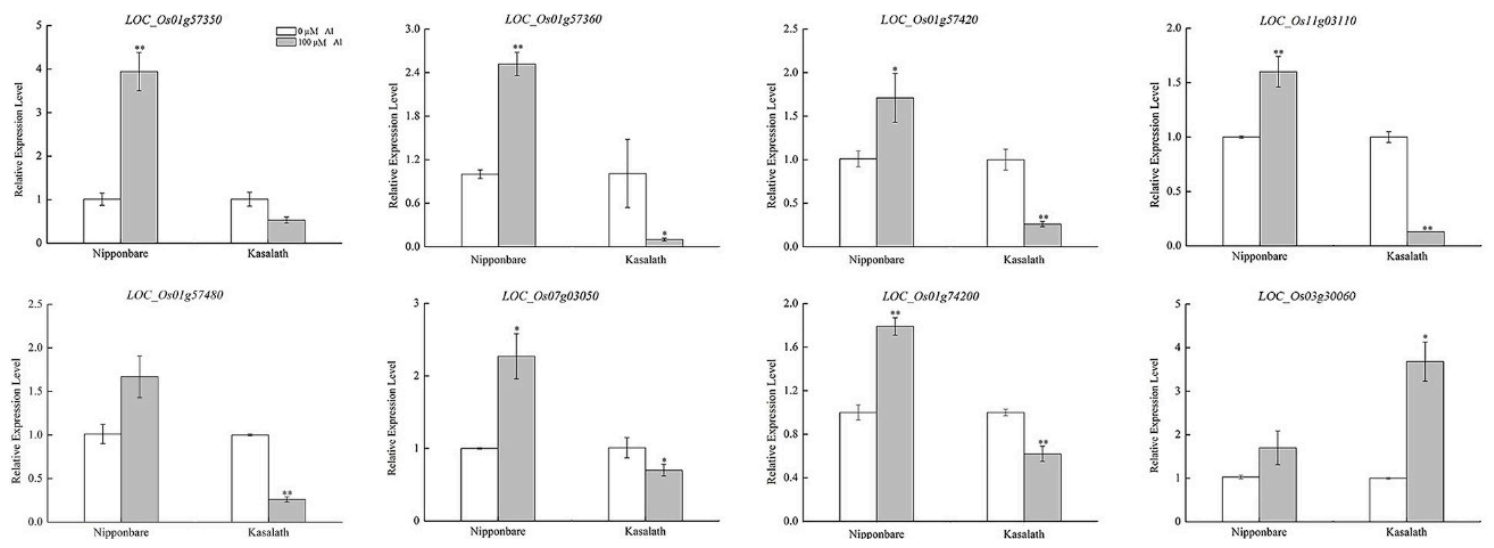

LOC_Os03230060

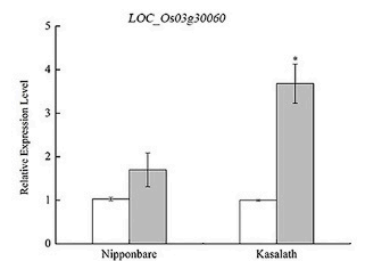

Figure 7. Expression of eight candidate genes in the rice root tip. ${ }^{*}$ and ${ }^{* *}$ represent significant differences at the $p<0.05$ and $p<0.01$ levels ( $t$-test), respectively.

\section{Discussion}

\subsection{Study of Al-Tolerance within Varieties in Different Subgroups, Based on Population Structure}

Al-tolerant and -sensitive accessions were discovered, both in Indica and Japonica rice $[7,10]$. Moreover, Al-tolerant mechanisms of rice were uncovered within Indica and Japonica rice in previous studies. For instance, one Al-tolerant Japonica variety named Azucena, and one Al-sensitive Indica variety named IR1552 were used in mapping Al-related QTL in rice $[15,19]$. Other studies focused on Al-tolerant and Al-sensitive Indica varieties named Xiangnuo 1 and Xiangzhongxian 2, respectively [20-22]. Huang et al. and Yamaji et al. uncovered Al-tolerance mechanisms in a Japonica variety, originating from Koshihikari, using one Al-sensitive and one Al-tolerant mutant, respectively [4,5]. One Al-tolerant Japonica variety, named Nipponbare, was used to identify Al-tolerant mechanisms in rice [23]. Wagatsuma et al. investigated the Al-tolerance mechanism with five temperate Japonica varieties, including two Al-sensitive and three Al-tolerant varieties, as well as one Al-sensitive Indica variety [24]. However, the Al-tolerant genotypes used in the previous studies were Japonica or mutants originating from Japonica. Besides, we speculated that the mechanisms between Japonica and Indica might not be common, according to the distinct ecological environment, especially the acidity level in the soil for Indica and Japonica rice. Thus, Al-tolerant and Al-sensitive varieties in the different subgroups, according to the population structure of Ting's core collection [25], were used to dissect the mechanisms of Al-tolerance in rice, in the present study. Choosing Indica- or Japonica-specific genes relating to Al-tolerance, using marker-assisted selection (MAS), would be very significant for the improvement of rice Al-tolerance.

\subsection{Different Gene Expression Patterns of Al-Tolerance between Indica and Japonica}

After the transcriptomic analysis, different gene expression patterns of Al-tolerant and Al-sensitive varieties in Indica and Japonica under Al toxicity were uncovered. Indica Al-tolerant and Japonica Al-tolerant strains had significantly different expression patterns before and after applying Al stress, while mixed Al-tolerant, which was inclined to Indica, had a similar expression pattern to Indica Al-tolerant. Moreover, Indica Al-sensitive and Japonica Al-sensitive strains had significantly different 
expression patterns before and after applying $\mathrm{Al}$ stress, and the mixed Al-sensitive, which was inclined to Japonica, had a similar expression pattern as Al-sensitive Japonica (Figure 4). As shown with a enrichment analysis of differentially expressed genes using website of g:Profiler (http:/ / biit.cs.ut.ee/ gprofiler/), differentially expressed genes were uniquely enriched into different terms for Al-tolerant Indica and Japonica. Some of the terms were reported to be related to plant Al-tolerance. For instance, it was demonstrated that the over-expression of one Al-induced gene parB (glutathione S-transferase) could ameliorate Al toxicity in Arabidopsis [26]. Differentially expressed genes, which are enriched in the "Structural constituent of ribosome", were found to be related to Al-tolerance in Stylosanthes [27].

\subsection{Different Pathways of Al-Tolerance between Indica and Japonica}

Al-tolerance in plants is a complex process that is mediated by various factors. In the present study, 11 pathways, which might be the difference for Al-tolerance between Indica and Japonica rice, were detected. Some of the pathways were reported to relate to Al-tolerance in other species; it was reported that hormonal equilibrium could be regulated by nitric oxide to improve Al-tolerance in the root apices of rye and wheat [28]. Ninety-two genes related to the plant hormone signaling transduction, pyruvate metabolism, amino sugar and nucleotide sugar metabolism, ribosome, the TCA cycle, the synthesis and degradation of ketone bodies, and butanoate metabolism, were enriched uniquely in Al-tolerant Indica (Table S2) and most of them have been reported to play important roles in Al-tolerance. For instance, LOC_Os08g39830 and LOC_Os03g53150, which regulate ethylene-insensitivity, respectively, [29,30] were expressed differentially after $\mathrm{Al}$ treatment in our study, and ethylene, as well as auxin could mediate the Al-induced inhibition of root elongation in Arabidopsis [31]. LOC_Os10g33800 and LOC_Os10g33800, belonging to the KEGG pathway of pyruvate metabolism and the TCA cycle, respectively, regulate the synthesis of malate dehydrogenase, which was over-expressed to confer tolerance to $\mathrm{Al}$ in alfalfa (Medicago sativa) [32]. Three genes were enriched uniquely in the KEGG pathway of sulfur metabolism in Al-tolerant Japonica (Table S3) and this pathway has been reported to be related to Al-tolerance [33]. For Al-sensitive Indica, 26 genes related to the pathways of amino sugars and nucleotide sugar metabolism, metabolic pathways, and starch and sucrose metabolism were enriched uniquely. Regarding amino sugar and nucleotide sugar metabolism, it has been reported that sugar concentrations increased with Al toxic treatment in rice [34].

\section{Materials and Methods}

\subsection{Plant Material}

Six varieties were chosen for transcriptomic analysis, according to the population structure existing in Ting's core collection [25]: two varieties (Al-tolerant and -sensitive) in the Indica subpopulation, two varieties (Al-tolerant and -sensitive) in the Japonica subpopulation, and two varieties (Al-tolerant and -sensitive) in the mixed subpopulation.

\subsection{Phenotyping for Al-Tolerance}

All of the rice seeds were harvested from the farm of the China National Rice Research Institute, Hangzhou $\left(30^{\circ} 3 \mathrm{~N}, 120^{\circ} 2 \mathrm{E}\right)$, during the late season (May-October) in 2014. A $1 \% \mathrm{H}_{2} \mathrm{O}_{2}$ solution was used to surface-sterilize 50 uniform seed of each rice variety. Deionized water was then used to wash the seeds three times. Next, the fifty seeds were soaked in $30^{\circ} \mathrm{C}$ temperature deionized water in a dark growth chamber for two days, in order for them to germinate. After germination, the seedlings were placed on a plastic net, which was put into a $1.5 \mathrm{~L}$ plastic container with $0.5 \mathrm{mmol} \cdot \mathrm{L}^{-1} \mathrm{CaCl}_{2}$ $(\mathrm{pH}=4.0)$ solution. We renew the $\mathrm{CaCl}_{2}$ solution on a daily basis. Precipitation of $\mathrm{Al}$ and other elements in Yoshida's solution [35]. will complicate Al-tolerance screening. It has been proven in many studies that the $\mathrm{CaCl}_{2}$ solution can effectively screen young seedlings whose seeds are still able to produce the essential mineral nutrients within Al-tolerant rice [6,9]. Thus, the $\mathrm{CaCl}_{2}$ solution was used instead of Yoshida's solution in this study. After $48 \mathrm{hr}$, the most uniform 20 seedlings were 
selected and used for $\mathrm{Al}$ toxicity treatment. We expose the 20 selected seedlings to $0.5 \mathrm{mmol} \cdot \mathrm{L}^{-1} \mathrm{CaCl}_{2}$ $(\mathrm{pH}=4.0)$ with $100 \mu \mathrm{mol} \cdot \mathrm{L}^{-1} \mathrm{AlCl}_{3}$. We expose control seedlings to $0.5 \mathrm{mmol} \cdot \mathrm{L}^{-1} \mathrm{CaCl}_{2}(\mathrm{pH}=4.0)$ only. We calculated RRE (RRE = root length under $\mathrm{Al}$ toxicity treatment/root length without $\mathrm{Al}$ toxicity treatment) after $24 \mathrm{hr}$, to evaluate the Al-tolerance of all varieties. Six replications were performed. During each replication, root lengths of 10 seedlings from each variety were measured using a ruler, and the measurements were recorded, both before the treatments and after the treatments $(14 \mathrm{hr})$. To measure Al-tolerance, we calculate the RRE value for each accession of the Ting's core collection. The criterion for finding out Al-tolerant varieties was RRE $\geq 0.5$ in the present study [36].

\subsection{Transcriptomic Analysis}

Total RNA of the root tip after $24 \mathrm{hr}$ under $100 \mu \mathrm{mol} \cdot \mathrm{L}^{-1} \mathrm{AlCl}_{3}$ was extracted with an miRNeasy Kit (QIAGEN, Germantown, MD, USA). The RNA samples were evaluated on agarose gels, quantified in a spectrophotometer, and stored at $-80^{\circ} \mathrm{C}$. RNA sequencing was performed by Illumina NextSeq 500 (San Diego, CA, USA) for $2 \times 125$-bp paired-end sequencing. Samples under Al toxic treatment (three times), and without $\mathrm{Al}$ toxic treatment (one time) were collected for RNA sequencing.

\subsection{Selecting Genes with Different Expression Patterns between Indica and Japonica}

We defined genes with the following attributes as having different expression patterns among Indica, Japonica, and mixed: (1) Genes were significantly up-regulated in one subgroup, but significantly down-regulated in the other subgroup; (2) Genes were significantly up-regulated or down-regulated in one subgroup, with a $\log _{2}$ (fold change) that was greater than or equal to 2 , but it did not have significant differential expression in the other subgroup. Genes with different expression patterns among the three subgroups were annotated with gene functions downloaded from UniProt [37].

\subsection{Gene Ontology Plots}

We used WEGO 2.0 (http:/ / wego.genomics.org.cn/) [38] to visualize the ontology of genes with different expression patterns between Indica and Japonica. GO plots for the tolerant varieties were plotted, using all genes with different expression levels between tolerant varieties in Indica and Japonica as candidates. In order for WEGO to generate a graph of genes with different expression levels between sensitive varieties in Indica and Japonica, genes were significantly up-regulated or down-regulated in one subgroup, with a $\log _{2}$ (fold change) of less than 2 , but those with no significant differential expression in the other subgroup were also used as candidates for WEGO.

\subsection{Heatmaps}

Heatmaps were graphed in R, using the gplots package [39]. Genes with different expression patterns between Indica and Japonica were chosen as candidates for heatmaps for all varieties.

\subsection{Real-Time $q R T-P C R$}

Nipponbare, a well-known Al-tolerant variety, and Kasalath, a well-known Al-sensitive variety, were chosen for real-time qRT-PCR analysis. The total RNA from a root tip after one day without treatment or under $100 \mu \mathrm{mol} \cdot \mathrm{L}^{-1} \mathrm{AlCl}_{3}$ was extracted with the miRNeasy Kit (QIAGEN, Germantown, MD, USA). RNA was converted to cDNA by using the protocol supplied by the manufacturer of ReverTra Ace qRT-PCR Master Mix with gDNA remover (TOYOBO, Shanghai, China). The expression was determined with the THUNDERBIRD ${ }^{\mathrm{TM}} \mathrm{SYBR}^{\circledR} \mathrm{qPCR}^{\mathrm{A}}$ Mix without ROX (TOYOBO, Shanghai, China) by Roche Light Cycler $^{\circledR}$ 480II (Roche, Basel, Switzerland). The primer sequences for qRT-PCR were $5^{\prime}$-AAGATCCACGTCGTCAAGGA-3' and $5^{\prime}$-CACTAACACTCCCAAGCCTC-3' for LOC_Os01g57450, 5' -TATGCCAGTGACCTTCAGCA-3' and 5'-GAGGTCAAGTGGTTCCGAGA-3' for LOC_Os01g74180, 5' -GTGGATTCGGTTGACACGAG-3' and 5'-TGCTGTGTGCGTACAGTAGA-3' for LOC_Os06g14030, 5' -CTTCAGGGCTCACTCCTTGA-3' and $5^{\prime}$-TTGTCGACGAAGAAGGTGGA-3' for 
LOC_Os07g03040, 5' -AATTGCCTGTGCCACCAAAT- $3^{\prime}$ and $5^{\prime}$-GTGTCCCTCCAAACTCCAGA-3' for LOC_Os07g03060, 5' -CGAGGGTTCCATCCTCTCAA-3' and 5'-TGTGCAAGCTCACATGCTAC- $3^{\prime}$ for LOC_Os07g03110, 5'-CTGCGAACGAGCTGATTAGG-3' and 5'-CATCTGAACACGCCACTGTC-3' for LOC_Os07g03140, 5' -GGTCAGCCAGCAAAGATCAG-3' and 5'-GATGCTCCTCCCTTTGGTCT-3' for LOC_Os07g03150, $5^{\prime}$-TCACACTGTCTGAGGAGCAG-3' and 5'-GTAGTCGCACAGCAGGAAAG-3' ${ }^{\prime}$ for LOC_Os07g29220, 5' ${ }^{\prime}$-AACGCGATGCAACGGTATAG-3' and 5' -CCACCGACGTTGAAGATGTC-3' for LOC_Os09g33550, $5^{\prime}$-AGCAGCCGCCATACTACTAC-3' and 5'-ATCCTCTGAGGAAGCCAAGG-3' for LOC_Os09g33559, and 5'-ACCGGCGATGTTAAGTTTGG-3' and 5'-CAATGAGCGTGTACCCATCG-3' for LOC_Os11g03110. Ubiquitin (forward primer, 5' -TGGTCAGTAATCAGCCAGTTTGG-3'; reverse primer, 5'-GCACCACAAATACTTGACGAACAG-3') was used as an internal control. Relative expression levels were calculated by the $2^{-\Delta \Delta C t}$ method. Three independent biological replicates were made for each treatment. The volume of the qRT-PCR reaction system was $10 \mu \mathrm{L}$ : SYBR Premix Ex Taq II, $2 \times, 5 \mu \mathrm{L}$; PCR -primer (Forward + Reverse, $10 \mathrm{uM}$ ), $2 \mu \mathrm{L}$; cDNA, $2 \mu \mathrm{L}$; $\mathrm{ddH}_{2} \mathrm{O}, 1 \mu \mathrm{L}$. The profile of the PCR program was $95^{\circ} \mathrm{C}$ for $3 \mathrm{~min} ; 45$ cycles of $95^{\circ} \mathrm{C}$ for $10 \mathrm{sec}, 58^{\circ} \mathrm{C}$ for $15 \mathrm{sec}$, $72{ }^{\circ} \mathrm{C}$ for $25 \mathrm{sec} ; 95^{\circ} \mathrm{C}$ for $10 \mathrm{sec} ; 65^{\circ} \mathrm{C}$ for $1 \mathrm{~min} ; 40^{\circ} \mathrm{C}$ for $1 \mathrm{~min}$.

Supplementary Materials: Supplementary materials can be found at http:/ / www.mdpi.com/1422-0067/20/4/ $997 /$ s1.

Author Contributions: P.Z. and H.T. conceived and designed the experiments. P.Z. performed the experiments. P.Z., Z.D., Z.Z. and H.T. analyzed the data. P.Z. and H.T. contributed reagents/materials/analysis tools. P.Z. and Z.D. wrote the paper.

Funding: This work was supported by a fund of the National Natural Science Foundation of China grant 31701401, funds of Zhejiang Province Public Welfare Technology Application Research Project (2016C32094 and LGN19C130005), a fund from Shanghai Agrobiological Gene Center (201503) and the State Key Laboratory for the Conservation and Utilization of Subtropical Agro-Bioresources (SKLCUSA-b201713).

Acknowledgments: Thanks goes to the anonymous reviewers.

Conflicts of Interest: The authors declare no conflict of interest.

\section{Abbreviations}

$\begin{array}{ll}\text { Al } & \text { Aluminum } \\ \text { RRE } & \text { Relative root elongation } \\ \text { QTL } & \text { Quantitative trait locus } \\ \text { DNA } & \text { Deoxyribonucleic acid } \\ \text { RNA } & \text { Ribonucleic acid } \\ \text { FPKM } & \text { Fragments per kilobase of exon model per million mapped reads } \\ \text { GO } & \text { Gene ontology } \\ \text { KEGG } & \text { Kyoto Encyclopedia of Genes and Genomics } \\ \text { qRT-PCR } & \text { Quantitative reverse transcription-PCR }\end{array}$

\section{References}

1. Vonuexkull, H.R.; Mutert, E. Global extent, development and economic impact of acid soils. Plant Soil 1995, 171, 1-15. [CrossRef]

2. Ismail, A.M.; Heuer, S.; Thomson, M.J.; Wissuwa, M. Genetic and genomic approaches to develop rice germplasm for problem soils. Plant Mol. Biol. 2007, 65, 547-570. [CrossRef] [PubMed]

3. Liu, J.; Luo, X.; Shaff, J.; Liang, C.; Jia, X.; Li, Z.; Magalhaes, J.; Kochian, L.V. A promoter-swap strategy between the AtALMT and AtMATE genes increased Arabidopsis aluminum resistance and improved carbon-use efficiency for aluminum resistance. Plant J. 2012, 71, 327-337. [CrossRef] [PubMed]

4. Huang, C.F.; Yamaji, N.; Mitani, N.; Yano, M.; Nagamura, Y.; Ma, J.F. A bacterial-type ABC transporter is involved in aluminum tolerance in rice. Plant Cell 2009, 21, 655-667. [CrossRef] [PubMed]

5. Yamaji, N.; Huang, C.F.; Nagao, S.; Yano, M.; Sato, Y.; Nagamura, Y.; Ma, J.F. A zinc finger transcription factor ART1 regulates multiple genes implicated in aluminum tolerance in rice. Plant Cell 2009, 21, 3339-3349. [CrossRef] [PubMed] 
6. Xia, J.; Yamaji, N.; Kasai, T.; Ma, J.F. Plasma membrane-localized transporter for aluminum in rice. Proc. Natl. Acad. Sci. USA 2010, 107, 18381-18385. [CrossRef] [PubMed]

7. Famoso, A.N.; Zhao, K.; Clark, R.T.; Tung, C.W.; Wright, M.H.; Bustamante, C.; Kochian, L.V.; McCouch, S.R. Genetic architecture of aluminum tolerance in rice (Oryza sativa) determined through genome-wide association analysis and QTL mapping. PLoS Genet. 2011, 7, e1002221. [CrossRef] [PubMed]

8. Li, J.Y.; Liu, J.; Dong, D.; Jia, X.; McCouch, S.R.; Kochian, L.V. Natural variation underlies alterations in Nramp aluminum transporter (NRAT1) expression and function that play a key role in rice aluminum tolerance. Proc. Natl. Acad. Sci. USA 2014, 17, 6503-6508. [CrossRef] [PubMed]

9. Yokosho, K.; Yamaji, N.; Fujii-Kashino, M.; Ma, J.F. Functional analysis of a MATE gene OsFRDL2 revealed its involvement in Al-induced secretion of citrate, but a lower contribution to Al tolerance in rice. Plant Cell Physiol. 2016, 57, 976-985. [CrossRef] [PubMed]

10. Zhang, P.; Zhong, K.; Tong, H.; Shahid, M.Q.; Li, J. Association mapping for aluminum tolerance in a core collection of rice landraces. Front. Plant Sci. 2016, 7, 1415. [CrossRef] [PubMed]

11. Arenhart, R.A.; Schunemann, M.; Bucker, N.L.; Margis, R.; Wang, Z.Y.; Margis-Pinheiro, M. Rice ASR1 and ASR5 are complementary transcription factors regulating aluminium responsive genes. Plant Cell Environ. 2016, 39, 645-651. [CrossRef] [PubMed]

12. Che, J.; Yamaji, N.; Shen, R.F.; Ma, J.F. An Al-inducible expansin gene, OsEXPA10 is involved in root cell elongation of rice. Plant J. 2016, 88, 132-142. [CrossRef] [PubMed]

13. Liu, S.; Gao, H.; Wu, X.; Fang, Q.; Chen, L.; Zhao, F.; Huang, C. Isolation and characterization of an aluminum-resistant mutant in rice. Rice 2016, 9, 60. [CrossRef] [PubMed]

14. Ma, J.F.; Furukawa, J. Recent progress in the research of external Al detoxification in higher plants: A mini review. J. Inorg. Biochem. 2003, 97, 46-51. [CrossRef]

15. Mao, C.; Yi, K.; Yang, L.; Zheng, B.; Wu, Y.; Liu, F.; Wu, P. Identification of aluminium-regulated genes by cDNA-AFLP in rice (Oryza sativa L.): Aluminium-regulated genes for the metabolism of cell wall components. J. Exp. Bot. 2004, 55, 137-143. [CrossRef] [PubMed]

16. Mao, C.; Yang, L.; Zheng, B.; Wu, Y.; Liu, F.; Yi, K.; Wu, P. Comparative mapping of QTL for Al tolerance in rice and identification of positional Al-induced genes. J. Zhejiang Univ. Sci. 2004, 5, 634-643. [CrossRef] [PubMed]

17. Nguyen, V.T.; Nguyen, B.D.; Sarkarung, S.; Martinez, C.; Paterson, A.H.; Nguyen, H.T. Mapping of genes controlling aluminum tolerance in rice: Comparison of different genetic backgrounds. Mol. Genet. Genom. 2002, 267, 772-780. [PubMed]

18. Xue, Y.; Jiang, L.; Su, N.; Wang, J.K.; Deng, P.; Ma, J.F.; Wan, J. The genetic basic and fine-mapping of a stable quantitative-trait loci for aluminium tolerance in rice. Planta 2007, 227, 255-262. [CrossRef] [PubMed]

19. Wu, P.; Liao, C.Y.; Hu, B.; Yi, K.K.; Jin, W.Z.; Ni, J.J.; He, C. QTLs and epistasis for aluminum tolerance in rice (Oryza sativa L.) at different seedling stages. Theor. Appl. Genet. 2000, 100, 1295-1303. [CrossRef]

20. Xu, H.S.; Gu, W.L.; Dong, D.F.; Peng, X.X. Differential resistance of two subtropical rice cultivars to aluminum toxicity. J. Plant Nutr. 2004, 27, 1601-1609. [CrossRef]

21. Yang, Q.; Wang, Y.; Zhang, J.; Shi, W.; Qian, C.; Peng, X. Identification of aluminum-responsive proteins in rice roots by a proteomic approach: Cysteine synthase as a key player in $\mathrm{Al}$ response. Proteomics 2007, 7, 737-749. [CrossRef] [PubMed]

22. Zhang, J.; He, Z.; Tian, H.; Zhu, G.; Peng, X. Identification of aluminium-responsive genes in rice cultivars with different aluminium sensitivities. J. Exp. Bot. 2007, 58, 2269-2278. [CrossRef] [PubMed]

23. Arenhart, R.A.; Bai, Y.; de Oliveira, L.F.; Neto, L.B.; Schunemann, M.; Maraschin, F.S.; Mariath, J.; Silverio, A.; Sachetto-Martins, G.; Margis, R.; et al. New insights into aluminum tolerance in rice: The ASR5 protein binds the STAR1 promoter and other aluminum-responsive genes. Mol. Plant 2014, 7, 709-721. [CrossRef] [PubMed]

24. Wagatsuma, T.; Maejima, E.; Watanabe, T.; Toyomasu, T.; Kuroda, M.; Muranaka, T.; Ohyama, K.; Ishikawa, A.; Usui, M.; Hossain, K.S.; et al. Dark conditions enhance aluminum tolerance in several rice cultivars via multiple modulations of membrane sterols. J. Exp. Bot. 2018, 69, 567-577. [CrossRef] [PubMed]

25. Zhang, P.; Li, J.; Li, X.; Liu, X.; Zhao, X.; Lu, Y. Population structure and genetic diversity in a rice core collection (Oryza sativa L.) investigated with SSR markers. PLoS ONE 2011, 6, e27565. [CrossRef] [PubMed] 
26. Ezaki, B.; Gardner, R.C.; Ezaki, Y.; Matsumoto, H. Expression of aluminium-induced genes in transgenic Arabidopsis plants can ameliorate aluminium stress and/or oxidative stress. Plant Physiol. 2000, 122, 657-665. [CrossRef] [PubMed]

27. Jiang, C.; Liu, L.; Li, X.; Han, R.; Wei, Y.; Yu, Y. Insights into aluminum-tolerance pathways in Stylosanthes as revealed by RNA-Seq analysis. Sci. Rep. 2018, 8, 6072. [CrossRef] [PubMed]

28. He, H.; He, L.; Gu, M.; Li, X. Nitric oxide improves aluminum tolerance by regulating hormonal equilibrium in the root apices of rye and wheat. Plant Sci. 2012, 183, 123-130. [CrossRef] [PubMed]

29. Yang, C.; Lu, X.; Ma, B.; Chen, S.; Zhang, J. Ethylene signaling in rice and Arabidopsis: Conserved and diverged aspects. Mol. Plant 2015, 8, 495-505. [CrossRef] [PubMed]

30. Kitomi, Y.; Inahashi, H.; Sato, Y.; Inukai, Y. OsIAA13-mediated auxin signaling is involved in lateral root initiation in rice. Plant Sci. 2012, 190, 116-122. [CrossRef] [PubMed]

31. Sun, P.; Tian, Q.; Chen, J.; Zhang, W. Aluminium-induced inhibition of root elongation in Arabidopsis is mediated by ethylene and auxin. J. Exp. Bot. 2010, 61, 347-356. [CrossRef] [PubMed]

32. Tesfaye, M.; Temple, S.; Allan, D.; Vance, C.; Samac, D. Overexpression of malate dehydrogenase in transgenic alfalfa enhances organic acid synthesis and confers tolerance to aluminum. Plant Physiol. 2001, 127, 1836-1844. [CrossRef] [PubMed]

33. Jiang, H.; Yang, L.; Qi, Y.; Lu, Y.; Huang, Z.; Chen, L. Root iTRAQ protein profile analysis of two Citrus species differing in aluminum tolerance in response to long-term aluminum-toxicity. BMC Genom. 2015, 16, 949. [CrossRef] [PubMed]

34. Moreno-Alvarado, M.; Garcia-Morales, S.; Trejo-Tellez, L.; Hidalgo-Contreras, J.; Gomez-Merino, F. Aluminum enhances growth and sugar concentration, alters macronutrient status and regulates the expression of NAC transcription factors in rice. Front. Plant Sci. 2016, 8, 73. [CrossRef] [PubMed]

35. Yoshida, S.; Fordo, D.A. Laboratory Manual for Plant Physiological Studies of Rice, 3rd ed.; International Rice Research Institute: Los Banos, Philippines, 1976.

36. Fu, X.L.; Chen, W.D.; Pan, C.H.; Feng, J.H.; Liu, X.D.; Lu, Y.G. A comparative study on aluminum tolerance between Oryza sativa and O. rufipogon in Gaozhou. J. Integr. Agr. 2010, 4, 661-669.

37. Rolf, A.; Amos, B.; Cathy, H.W.; Winona, C.B.; Brigitte, B.; Serenella, F.; Elisabeth, G.; Hongzhan, H.; Rodrigo, L.; Michele, M.; et al. UniProt: The Universal Protein knowledgebase. Nucleic Acids Res. 2004, 32, D115-D119.

38. Ye, J.; Fang, L.; Zheng, H.K.; Chen, J.; Zhang, Z.J.; Wang, J.; Li, S.T.; Li, R.Q.; Bolund, L.; Wang, J. WEGO: A web tool for plotting GO annotations. Nucleic Acids Res. 2006, 34, W293-W297. [CrossRef] [PubMed]

39. Gregory, R.; Warnes, B.B.; Lodewijk, B. gplots: Various R Programming Tools for Plotting Data. R Package Version 3.0.1.1. Available online: https:// cran.r-project.org/web/packages/gplots/index.html (accessed on 27 January 2019).

(C) 2019 by the authors. Licensee MDPI, Basel, Switzerland. This article is an open access article distributed under the terms and conditions of the Creative Commons Attribution (CC BY) license (http://creativecommons.org/licenses/by/4.0/). 